Article

\title{
Carbon Emission Calculation Method and Low-Carbon Technology for Use in Expressway Construction
}

\author{
Bo Peng ${ }^{1}$, Xiaoying Tong ${ }^{1,2, *}$, Shijiang Cao ${ }^{3}$, Wenying $\mathrm{Li}^{4}$ and Gui Xu ${ }^{1}$ \\ 1 School of Highway, Chang'an University, Xi'an 710064, China; pengb8888@chd.edu.cn (B.P.); \\ guixu@chd.edu.cn (G.X.) \\ 2 Shaanxi Institute of Urban \& Rural Planning and Design, Xi'an 710021, China \\ 3 China National Construction Group Guiyang Survey Design and Research Institute Co., Ltd., \\ Guiyang 550081, China; 2015221166@chd.edu.cn \\ 4 Xi'an Highway Research Institute, Xi'an 710065, China; lwynn203@chd.edu.cn \\ * Correspondence: xiaoying@chd.edu.cn
}

Received: 29 February 2020; Accepted: 14 April 2020; Published: 16 April 2020

\begin{abstract}
There is a need for a quantitative calculation method for carbon emissions during asphalt pavement construction. In this study, the carbon sources were detected and carbon emission during pavement construction was divided into two parts- the emission resulting from energy consumption and that arising from the volatilization of asphalt mixtures itself. The carbon emission calculation model of energy consumption is presented based on the energy consumption list and calorific value method proposed by the Intergovernmental Panel on Climate Change. The model of the carbon emission from volatilization of asphalt mixtures was introduced based on a combination of on-site inspection data and the greenhouse gas diffusion rate and calculated volume. Finally, high-carbon emission processes and total carbon emissions were obtained, and the corresponding low-carbon technologies were proposed for different types of carbon emissions. The results show that the ratio of carbon emission generated by energy consumption and the volatilization of asphalt mixtures is 3:2; aggregate and asphalt heating are high-carbon emission processes of energy consumption, while asphalt mixture rolling and mixing are the high-carbon emission processes of asphalt mixture. Furthermore, the use of natural gas can control carbon emission in energy consumption; low-carbon asphalt mixtures and warm mixing technology can effectively reduce carbon emission from the volatilization of asphalt mixtures. This study lays a theoretical foundation for green pavement construction.
\end{abstract}

Keywords: road engineering; calculation model; carbon emission of energy consumption; carbon emission from volatilization of asphalt mixture; low-carbon technology

\section{Introduction}

With the increase in greenhouse gas emissions, the world is witnessing the continuous melting of polar ice circles and frequently occurring extreme weather events due to global warming. These effects of global warming have seriously threatened the production and life of humans; thus, the control and reduction of greenhouse gas emissions have become an urgent problem [1-3]. The road traffic industry is one of the main sources of carbon emissions locally as well as internationally, especially during the construction process of expressway asphalt pavements (i.e., roads that have no stop signs or signals, with traffic travelling in one direction separated from the traffic travelling in the opposite direction). Reducing the carbon emissions generated during construction is therefore an important research field to address global warming [4-6]. 
Many researchers have conducted related researches on the calculation methods of carbon emissions during asphalt pavement construction [7-10]. The conventional method employs the life-cycle assessment (LCA) theory to conduct stage division and calculate carbon emissions. Cass et al. collected data on the production, transportation, construction machinery, and other materials involved in highway overhaul engineering and established the life-cycle analysis model of carbon emission arising from energy consumption [11]. Wang et al. described a pavement life-cycle assessment model developed to evaluate energy use and greenhouse gas emissions from pavement rehabilitation strategies [12]. Wang et al. focused on quantifying the environmental impact of asphalt pavement preservation at the construction and use stages using the life-cycle assessment approach [13]. White et al. considered the carbon emission of different pavement types during road material production and construction and established a carbon emission calculation model by considering road width, material characteristics, road thickness, and service life as calculation parameters [14]. Kleine et al. investigated the limitations of life-cycle analyses and proposed a calculation method based on road construction quota [15]. Aurangzeb et al. used the hybrid life-cycle analysis to analyze the environmental footprint of using a reclaimed asphalt pavement (RAP) content in asphalt binder mixtures [16]. However, a certain lag occurs in the data when the calculation is based on construction quota, and thus, the data fails to reflect the actual carbon emission from energy consumption. In these studies, carbon emission from the volatilization of asphalt mixtures itself due to the decrease of mixture temperature was ignored. Furthermore, these calculation methods seriously affect the total carbon emission value attributed to the asphalt pavement construction industry and fail to provide effective guidance for low-carbon emission technology for asphalt pavements. In addition, Giunta et al. and Praticò et al. dealt with the life-cycle assessment of different classes of pavement technologies, based on the use of bituminous mixes (hot mix asphalt and warm mix asphalt) with recycled materials (reclaimed asphalt pavements, crumb rubber, and waste plastics), in the pursuit of assessing energy and environmental impacts $[17,18]$. Sara et al. compared the different alternative bituminous sub-ballast mixtures containing recycled materials, namely crumb rubber (CR) and reclaimed asphalt pavements (RAP) by means of the results of a life-cycle assessment [19]. The main purpose of this study is to put forward a more accurate quantitative calculation model of carbon emission from the asphalt pavement of expressway construction, and on this basis, according to different carbon emission sources, put forward a targeted emission reduction technology. The carbon emission of expressway construction contains material preparation, transportation and on-site construction. Due to the inaccurate statistics of total carbon emission during construction, it is impossible to accurately assess the impact of greenhouse gases on the environment. In this study, carbon emission during the asphalt pavement of expressway construction was classified based on the carbon sources detected; using this classification and considering the construction processes, calculation models were established for different types of carbon emissions. Finally, the total carbon emissions of 12 expressways in China and the effect of emission reduction technologies were calculated in case studies. In these case studies, model reliability was demonstrated, and carbon emissions were reduced. The research results will provide powerful support for further environmental protection policies and construction.

\section{Establishing a Calculation Method for the Carbon Emission of Asphalt Pavements}

The existing research methods mainly calculate carbon emissions based on the construction quota. There is a lack of research on the carbon emissions from the volatilization of asphalt mixtures itself. Hence, in this study, two types of carbon emission calculation models were developed based on carbon sources. Carbon emission surveys of various construction processes were conducted to build the models. The models visually compare the carbon emissions of various processes and facilitate the identification of their high-carbon emission processes to implement the targeted carbon emission reduction technology. 


\subsection{Carbon and Energy Consumption Sources}

The existing studies have indicated that the greenhouse effect is caused by various gases. Among these gases, $\mathrm{CO}_{2}, \mathrm{CH}_{4}$, and $\mathrm{N}_{2} \mathrm{O}$ are the main gases that considerably affect human activities and have significant greenhouse effects [20-23]. $\mathrm{CO}_{2}$ is the greatest contributor, accounting for $86 \%$ of the greenhouse gases. Therefore, in this study, carbon emission is regarded as a general term for greenhouse gases [24-26]. Dividing the construction processes is necessary to calculate the carbon emission in asphalt pavement construction accurately and conveniently. Although the specific construction techniques of individual expressways are different, the overall construction sequence is approximately the same and is mainly divided into the following eight processes: yard stacking, aggregate feeding, aggregate heating, asphalt heating, mixing, transportation, paving, and rolling. On-site investigation was conducted, and carbon sources were detected; carbon emission during asphalt pavement construction was classified into two categories. The first category is the carbon emission generated by the energy consumption of vehicles, machinery, and equipment-this category is called the carbon emission in energy consumption [27,28]. The second category is the greenhouse gas emitted from the volatilization of asphalt mixtures itself-this category is referred to as the carbon emission from the volatilization of the asphalt mixture.

The current research was supported by the carbon emission investigation and detection data of 12 expressways in North China, Central China, Northwest China, and Southwest China. In the eight construction processes, pavement structure, equipment model, production capacity, energy type, energy consumption, asphalt mixture type, asphalt-aggregate ratio, paving width, pavement core drilling sampling density, and other factors cause different sources of greenhouse gases. Besides, different geographical locations and climate environments lead to different actual operations of the same construction process. Therefore, it is necessary to investigate and test the types and amount of carbon emissions generated in multiple regions and different construction processes. The carbon sources of all of the processes are listed in Table 1.

Table 1. Carbon sources of each process in asphalt pavement construction.

\begin{tabular}{ccc}
\hline Carbon Source & Energy Consumption & $\begin{array}{c}\text { The Volatilization of the Asphalt } \\
\text { Mixtures Itself }\end{array}$ \\
\hline Yard stacking & Loader/Diesel & $/$ \\
Aggregate feeding & Loader/Diesel & $/$ \\
Aggregate heating & Drying drum/Heavy oil & $/$ \\
Asphalt heating & Heating equipment with heat transfer oil as carrier/Coal & $/$ \\
Mixing & Batch asphalt mixing equipment/Electric & Volatilization \\
Transporting & Truck/Diesel & Volatilization \\
Paving & Spreading machine/Diesel & Volatilization \\
Rolling & Roller/Diesel & Volatilization \\
\hline
\end{tabular}

Note: field investigations and statistical statements were adopted for detecting carbon emission from energy consumption; on-site inspections were used for detecting carbon emission from volatilization of asphalt mixture.

Letters $\mathrm{A}$ to $\mathrm{L}$ are used to represent the 12 expressways and $M$ represents the energy consumption. The energy consumption generated by yard stacking $\left(\mathrm{M}_{1}\right)$, aggregate feeding $\left(\mathrm{M}_{2}\right)$, aggregate heating $\left(\mathrm{M}_{3}\right)$, and mixing $\left(\mathrm{M}_{5}\right)$ were obtained through field investigation. Asphalt heating $\left(\mathrm{M}_{4}\right)$ is calculated as $\mathrm{M}_{4}=\mathrm{a} \times \mathrm{m} / 1+\mathrm{a}$, where $\mathrm{a}$ is the asphalt-aggregate ratio and $\mathrm{m}$ is the energy consumption when heating 1 ton of asphalt. $\mathrm{M}_{6}$ is the energy consumption of transporting 1 ton of asphalt mixture for $1 \mathrm{~km} ; \mathrm{M}_{7}$ is the energy consumption of paving 1 ton of asphalt mixture; and $\mathrm{M}_{8}$ is the energy consumption after the application of initial compaction, recompaction, and final compaction to 1 ton of asphalt mixture. The investigation and detection data were calculated by taking the average as the representative value based on standard deviation and variability analysis. The energy consumptions of all of the processes are listed in Table 2. 
Table 2. Energy consumption of each process in asphalt pavement construction.

\begin{tabular}{|c|c|c|c|c|c|c|c|c|}
\hline Process/ $\mathbf{M}_{\mathbf{i}}$ & $\mathbf{M}_{1}$ & $\mathbf{M}_{2}$ & $\mathbf{M}_{3}$ & $\mathbf{M}_{4}$ & $\mathbf{M}_{5}$ & $\mathbf{M}_{6}$ & $\mathbf{M}_{7}$ & $\mathbf{M}_{8}$ \\
\hline $\begin{array}{l}\text { Energy/ } \\
\text { (unit) }\end{array}$ & $\begin{array}{l}\text { Diesel/ } \\
\left(L^{-} \cdot t^{-1}\right)\end{array}$ & $\begin{array}{l}\text { Diesel/ } \\
\left(\mathrm{L} \cdot \mathrm{t}^{-1}\right)\end{array}$ & $\begin{array}{c}\text { Heavy Oil/ } \\
\left(\mathbf{k g} \cdot \mathrm{t}^{-1}\right)\end{array}$ & $\begin{array}{c}\text { Coal/ } \\
\left(\mathrm{kg} \cdot \mathrm{t}^{-1}\right)\end{array}$ & $\begin{array}{c}\text { Electric/ } \\
\text { (kw.h) }\end{array}$ & 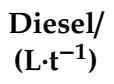 & $\begin{array}{l}\text { Diesel/ } \\
\left(L^{-} \cdot t^{-1}\right)\end{array}$ & $\begin{array}{l}\text { Diesel/ } \\
\left(L^{\prime} \cdot \mathbf{t}^{-1}\right)\end{array}$ \\
\hline A & 0.152 & 0.173 & 6.310 & 1.223 & 3.214 & 0.058 & 0.182 & 0.373 \\
\hline B & 0.120 & 0.166 & 6.482 & 1.745 & 3.215 & 0.031 & 0.232 & 0.329 \\
\hline $\mathrm{C}$ & 0.137 & 0.216 & 6.524 & 1.832 & 3.206 & 0.036 & 0.232 & 0.329 \\
\hline D & 0.113 & 0.162 & 5.609 & 2.604 & 2.850 & 0.052 & 0.160 & 0.275 \\
\hline $\mathrm{E}$ & 0.135 & 0.152 & 7.013 & 1.536 & 3.072 & 0.047 & 0.172 & 0.386 \\
\hline $\mathrm{F}$ & 0.122 & 0.148 & 6.429 & 2.563 & 4.357 & 0.061 & 0.257 & 0.403 \\
\hline G & 0.112 & 0.160 & 6.635 & 2.353 & 3.152 & 0.038 & 0.144 & 0.337 \\
\hline $\mathrm{H}$ & 0.125 & 0.159 & 7.106 & 1.983 & 3.441 & 0.047 & 0.182 & 0.260 \\
\hline I & 0.136 & 0.148 & 6.620 & 1.703 & 3.739 & 0.042 & 0.165 & 0.273 \\
\hline G & 0.121 & 0.152 & 5.857 & 1.308 & 3.478 & 0.063 & 0.155 & 0.213 \\
\hline $\mathrm{K}$ & 0.119 & 0.145 & 7.318 & 2.651 & 2.330 & 0.035 & 0.133 & 0.267 \\
\hline $\mathrm{L}$ & 0.126 & 0.223 & 6.501 & 1.432 & 2.247 & 0.025 & 0.163 & 0.393 \\
\hline
\end{tabular}

Note: A: Jingqin Expressway; B: Jishan Expressway; C: Huangyan Expressway; D: Sancha Expressway; E: Xixian Expressway; F: Pengteng Expressway; G: Liaoyu Expressway; H: G3014; I: G310; J: Yanyan Expressway; K: West Copper Expressway; and L: Binhai Expressway.

\subsection{Carbon Emission Arising from Energy Consumption}

Carbon source analysis showed that carbon emission from energy consumption is mainly caused by the burning of various fossil fuels. Therefore, this type of emission is quantified based on the energy consumption (Table 2) and then considered in the calorific value method to calculate carbon emission in energy consumption during asphalt pavement construction.

For the quantitative standard and calculation parameters of carbon emission in energy consumption, the details are as follows:

Before establishing calculation models for carbon emission from energy consumption, appropriate technical indicators and calculation parameters should be selected for the unification and standardization of the calculation.

(1) Quantitative standard

Considering the differences in heavy traffic and regions that produce different bituminous structures, these functional units result in the inaccurate quantification of carbon emission from energy consumption. In this study, the production or construction of 1 ton of the asphalt mixture was used as the quantitative calculation standard to reduce the influence of the above factors.

(2) Calculation parameters

$Q$ is used as the energy calorific value for various energy sources provided by the National Bureau of Statistics [29]. The energy carbon emission factor $(E F)$ provided by the IPCC (Intergovernmental Panel on Climate Change) was used to characterize the capability of energy consumption to generate greenhouse gases [30,31]. The calorific value of energy and energy carbon EF are listed in Table 3. The global warming potential (GWP) proposed by the IPCC in the Comprehensive Report on Climate Change 2014 was used to characterize the ratio of different greenhouse gases to equivalent carbon dioxide, and accordingly, the GWP of $\mathrm{CO}_{2}$ was found to be 1; that of $\mathrm{CH}_{4}, 25$; and that of $\mathrm{N}_{2} \mathrm{O}, 298$ [32].

Table 3. Calorific value of energy and Energy carbon emission factor $(E F)$.

\begin{tabular}{cccccc}
\hline \multicolumn{2}{c}{ Energy Type } & Coal & Heavy Oil & Diesel & Natural Gas \\
\hline \multirow{2}{*}{$Q /(\mathrm{MJ} / \mathrm{kg})$} & & 20.908 & 41.816 & 42.652 & 38.931 \\
& $\mathrm{CO}_{2}$ & 94,600 & 77,400 & 74,100 & 56,100 \\
$E F /(\mathrm{mg} / \mathrm{MJ})$ & $\mathrm{CH}_{4}$ & 1 & 3 & 3 & 1 \\
& $\mathrm{~N}_{2} \mathrm{O}$ & 1.5 & 0.6 & 0.6 & 0.1 \\
\hline
\end{tabular}


For calculation models for carbon emission from energy consumption, the details are as follows.

Based on the calorific value equation, combined with the type of carbon emission provided by the IPCC [30] and the unit conversion method, the calculation method for carbon emission from energy consumption is as follows:

$$
E_{e}=M \cdot Q \cdot E F
$$

where $E_{e}$ is the carbon emission from energy consumption $(\mathrm{kg} / \mathrm{t}) ; M$ is the energy consumption of solid and liquid $(\mathrm{kg})$, or gas $\left(\mathrm{m}^{3}\right) ; Q$ is the energy calorific value $(\mathrm{MJ} / \mathrm{kg})$; and $E F$ is the energy carbon emission factor (mg/MJ).

Considering that Equation (1) can be used only to calculate the $\mathrm{CO}_{2}$ emissions, it is necessary to convert the values for $\mathrm{CH}_{4}$ and $\mathrm{N}_{2} \mathrm{O}$ into $\mathrm{CO}_{2}$-equivalent values combined with the GWP. Moreover, it is necessary to develop different carbon emission calculation models for specific construction processes of asphalt pavements because of the different energy types and measurement units involved in each construction process. The calculation models of various processes and different greenhouse gases were determined by combining the proposed quantitative standard and energy combustion characteristics as follows.

(1) Calculation model for the carbon emission of diesel:

$$
E_{e i}=V_{i} \cdot \rho_{i} \cdot \eta_{i} \cdot Q_{i} \sum_{j=1}^{3} G W P_{j} \cdot E F_{j}
$$

(2) Calculation model for the carbon emission of coal or heavy oil:

$$
E_{e i}=m_{i} \cdot \eta_{i} \cdot Q_{i} \sum_{j=1}^{3} G W P_{j} \cdot E F_{j}
$$

(3) Calculation model for the total carbon emission from energy consumption:

$$
E_{e}=\sum_{i=1}^{8} E_{e i}(i \neq 5)
$$

where $i$ represents the construction process; $i=1-8$ represent yard stacking, aggregate feeding, aggregate heating, asphalt heating, asphalt mixture mixing, transporting, paving, and rolling, respectively; $j$ represents the type of greenhouse gas, and $j=1,2$, and 3 represent $\mathrm{CO}_{2}, \mathrm{CH}_{4}$, and $\mathrm{N}_{2} \mathrm{O}$, respectively. $E_{e i}$ is the carbon emission of energy consumption $(\mathrm{kg} / \mathrm{t}) ; V_{i}$ is the volume of diesel consumption $(\mathrm{L} / \mathrm{t})$; $\rho_{i}$ is the density of diesel $\left(\mathrm{g} / \mathrm{cm}^{3}\right) ; \eta_{i}$ is the oxidation rate of energy combustion (\%); $m_{i}$, is the mass of coal or heavy oil consumption $(\mathrm{kg} / \mathrm{t}) ; G W P_{j}$ is the global warming potential; and $E_{e}$ is the total carbon emission of energy consumption $(\mathrm{kg} / \mathrm{t})$. When $i=5$, the carbon emission of energy consumption during mixing is not considered because electric energy is used for mixing, and hence this process does not directly generate carbon emissions.

\subsection{Carbon Emission from Volatilization of Asphalt Mixture}

The carbon emission from the volatilization of asphalt mixtures itself mainly occurs in the following four construction processes: asphalt mixture mixing, transportation, paving, and rolling. Concentration of the greenhouse gases from the volatilization of asphalt mixtures itself adopted the on-site inspections method. The detection instrument was the ZR-3100 multigas detector, which consists of a gas collection device, a dust filter device, a cooling device, a host, a printer, and other parts. Different gases are identified by different sensors. Each sensor can only identify one gas. The thermometers and gas detectors used in the study are shown in Figure 1. 

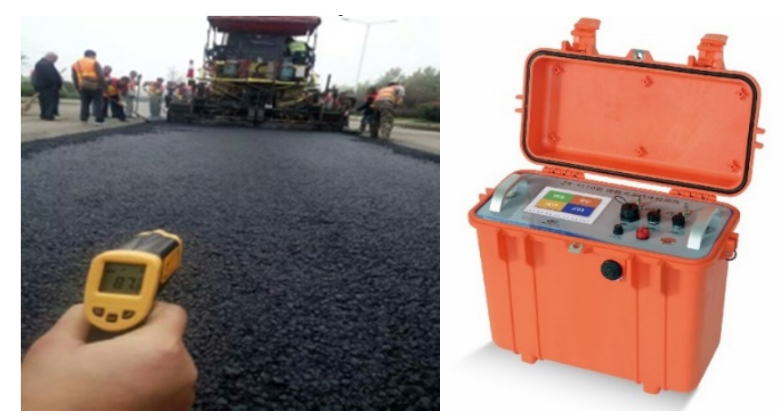

Figure 1. The thermometer (left) and the ZR-3100 multigas detector (right).

First, the ZR-3100 multigas detector can be used to measure the volume concentration or percentage concentration of the greenhouse gases. Then, the mass concentration can be calculated according to the conversion models and combined with the relevant parameters of the detected greenhouse gas. Finally, the calculation models for carbon emission from the volatilization of the asphalt mixture can be established.

For calculation parameters for the carbon emission from the volatilization of asphalt mixtures, the details are as follows:

(1) Determining the mass concentration

The detected greenhouse gases comprise $\mathrm{CO}_{2}, \mathrm{CH}_{4}$, and $\mathrm{N}_{2} \mathrm{O}$. The calculation models are based on mass concentration, while the detected $\mathrm{CO}_{2}$ and $\mathrm{N}_{2} \mathrm{O}$ are presented in terms of their volume concentration and the combustible gas $\mathrm{CH}_{4}$, in terms of its percentage concentration. Hence, the percentage concentration of $\mathrm{CH}_{4}$ must be converted to volume concentration to facilitate a unified calculation, and then the volume concentrations of the three greenhouse gases should be converted into mass concentration. The relative molecular masses of $\mathrm{CO}_{2}, \mathrm{CH}_{4}$, and $\mathrm{N}_{2} \mathrm{O}$ are 44,16 , and 44, respectively, and their conversion models are shown in Equations (5) and (6).

(1) Conversion model for the volume concentration of combustible gas $\mathrm{CH}_{4}$ :

$$
C_{v}=\% L E L \times L E L(V O L \%) \times 100
$$

(2) Three mass concentration conversion models of the three greenhouse gases:

$$
\rho_{i j}=\frac{M}{22.4} \times C_{v} \times\left[\frac{273}{273+T} / \frac{B a}{101325}\right]
$$

where $C_{v}$ is the volume concentration; \%LEL is the volume percentage concentration; LEL (VOL\%) is the lower limit of the corresponding explosion range of combustible gas (the lower limit of explosion is $5 \% V O L) ; \rho_{i j}$ is the mass concentration $\left(\mathrm{mg} / \mathrm{m}^{3}\right) ; M$ is the relative molecular mass; $T$ is the atmospheric temperature $\left({ }^{\circ} \mathrm{C}\right)$; and $B_{a}$ is the atmospheric pressure $\left(\mathrm{P}_{\mathrm{a}}\right)$.

(2) Calculating the volume

The calculation diagram for carbon emission from the volatilization of asphalt mixtures based on the characteristics and modes of greenhouse gas movement is shown in Figure 2. 


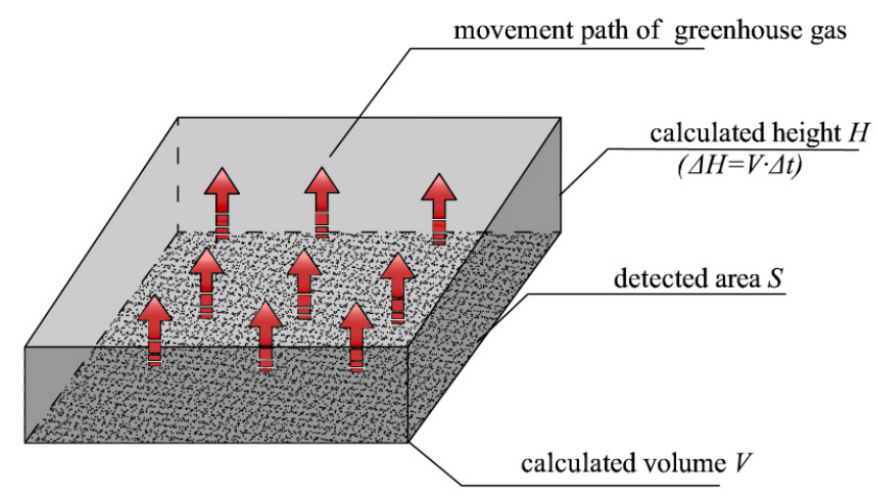

Figure 2. Schematic regarding carbon emission from the volatilization of asphalt mixtures.

In Figure 2, detected area $S$ is the contact surface of the asphalt mixture with atmosphere. This surface is mainly determined by the detection scheme in the carbon emission of the asphalt mixture. Calculated height $H$ refers to the diffusion height of the carbon emission from volatilization of asphalt mixtures itself at $\Delta t$ time, and calculated volume $V$ is the product of calculated surface area $S$ and height $H$.

(3) Determining the diffusion rate of greenhouse gases

The method is to connect the outlet of the mixing process with a thick conduit and seal it all around, and then use the gas mass concentration detector to start timing from the moment when the hose contacts the mixture until the measured gas mass concentration reaches a certain initial value. Finally, the diffusion rate of greenhouse gases is calculated according to the measured length and time of the conduit. Besides, the diffusion rate of a greenhouse gasses is closely related to the temperature of the asphalt mixture. The relationship between the gas diffusion rate and mixture temperature was fitted through testing as shown in Figure 3.

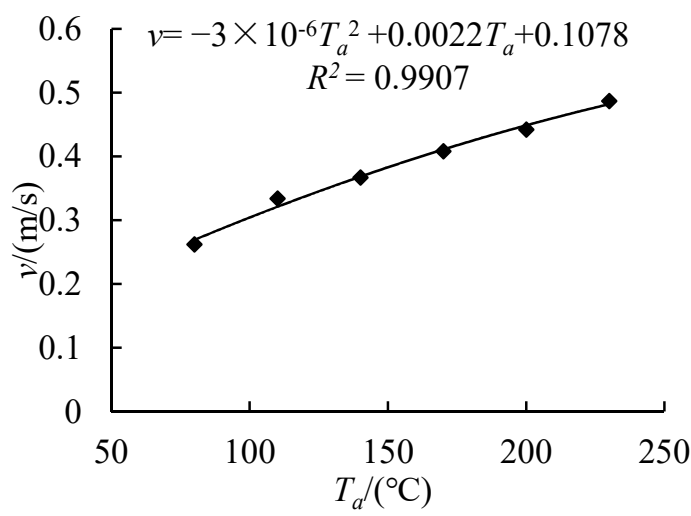

Figure 3. Relationship between gas diffusion rate and mixture temperature.

Figure 3 shows that the gas diffusion rate increases with the asphalt mixture temperature. The diffusion rates at different temperatures can be determined based on this relationship, thereby providing a foundation for determining the calculated height $H$ of carbon emission of the asphalt mixture. Thus, the calculation model of carbon emission from the volatilization of asphalt mixtures was established based on the conversion models for volume and mass concentrations and the calculated volume and gas diffusion rate.

For the carbon emission calculation model of asphalt mixture volatilization, the details are as follows: 
Carbon emission calculation models were developed based on proposed calculation parameters and on-site detection data and actual construction conditions:

$$
\left\{\begin{array}{l}
E_{\mathcal{C}}=\frac{V \cdot \sum_{j=1}^{2}\left(\rho_{i j} \cdot G W P_{j}\right)}{10^{6} G} \\
V=S \cdot H
\end{array}\right.
$$

where $E_{c}$ is the carbon emission from the volatilization of the asphalt mixture $(\mathrm{kg} / \mathrm{t}) ; V$ is the calculated volume $\left(\mathrm{m}^{3}\right) ; \rho$ is the mass concentration of the greenhouse gas $\left(\mathrm{mg} / \mathrm{m}^{3}\right) ; G$ is the mass of the tested (t) mixture; $S$ is the detected area $\left(\mathrm{m}^{2}\right)$; and $H$ is the calculated height of the greenhouse gas $(\mathrm{m})$.

Although the calculation concept of asphalt mixtures in each process of construction is similar, the methods to determine the calculated area, height, and mass vary because of the differences in the characteristics and detection methods for different construction processes. Therefore, it is necessary to revise Equation (7) and establish an equation suitable for each process to obtain a practical, scientific, and effective calculation.

(1) Carbon emission calculation model of asphalt mixtures during mixing

In the mixing process, the type of mixing plant used was "NBD320ABZ" (the building that mixes the asphalt, crushed stone, ore powder, etc., in a certain proportion, and then heats and stirs then to produce the asphalt mixture), the detection point was located above the outlet of the mixing plant, and 15 samples were taken from each detection point. Based on the investigation, mass $G_{1}$ of the asphalt mixture in the mixing stage was determined. The discharging time is short, and the mixture temperature changes slightly, as shown in the relationship between the gas diffusion rate and temperature (Figure 3). The variation in the gas diffusion rate is small, and the height $H=\int_{0}^{t} v \cdot d t=v t$ is calculated. The cross section of the discharge opening of the mixing building was selected as detected area $S_{1}$, and thus calculated volume $V_{1}$ can be obtained. The calculation model of mixing is thus obtained as shown in Equation (8):

$$
\left\{\begin{array}{l}
E_{c 5}=\frac{V_{1} \cdot \sum_{j=1}^{3}\left(\rho_{5 j} \cdot G W P_{j}\right)}{10^{6} G_{1}} \\
V_{1}=S_{1} \cdot v_{1} \cdot t_{1}
\end{array}\right.
$$

where $E_{c 5}$ is the carbon emission of the asphalt mixture during mixing $(\mathrm{kg} / \mathrm{t}) ; v_{1}$ is the diffusion rate of the greenhouse gas from the outlet of the mixing building $(\mathrm{m} / \mathrm{s}) ; t_{1}$ is the discharging time of the asphalt mixture (s); $S_{1}$ is the detected area of the mixing building $\left(\mathrm{m}^{2}\right) ; \rho_{5 j}$ is the greenhouse gas mass concentration $\left(\mathrm{mg} / \mathrm{m}^{3}\right)$; and $G_{1}$ is the amount of mixture discharged from the mixing building $(\mathrm{t})$.

(2) Carbon emission calculation model of asphalt mixtures during transportation

Asphalt mixtures have a high temperature after discharging and carbon emission occurs during their transportation. The ZR-3100 multigas detector was used to detect on the top of the trucks, the side of the mixture that was not in contact with the truck was the inspection side, and the 15 sampling points were distributed around the top of the vehicle. Detected area $S_{2}$ is considered the contact surface between the asphalt mixture and the air inside the vehicle and is determined from the length and width of the vehicle. Generally, mixing stations are located close to the construction site. In addition, thermal insulation measures are usually adopted during the transportation of the asphalt mixture. Hence, the changes in temperature and gas diffusion rate are small. Thus, the calculated height of transportation is similar to that of mixing. Furthermore, the carbon emission for a transportation distance of $1 \mathrm{~km}$ is uniformly used for comparison to avoid the impact of different transportation distances. The established calculation model is shown in Equation (9):

$$
\left\{\begin{array}{l}
E_{c 6}=\frac{V_{2} \cdot \sum_{j=1}^{3}\left(\rho_{6 j} \cdot G W P_{j}\right)}{10^{6} G_{2}} \\
V_{2}=S_{2} \cdot v_{2} \cdot t_{2}
\end{array}\right.
$$


where $E_{c 6}$ is the carbon emission of the asphalt mixture during transportation $(\mathrm{kg} / \mathrm{t}) ; v_{2}$ is the diffusion rate of the greenhouse gas during transportation $(\mathrm{m} / \mathrm{s}) ; t_{2}$ is the time taken for the transport vehicle to travel $1 \mathrm{~km}(\mathrm{~s}) ; S_{2}$ is the carriage area of the transport vehicle $\left(\mathrm{m}^{2}\right) ; \rho_{6 j}$ is the greenhouse gas mass concentration during transportation $\left(\mathrm{mg} / \mathrm{m}^{3}\right)$; and $G_{2}$ is the carrying capacity of the transport vehicle $(\mathrm{t})$.

(3) Carbon emission calculation model of asphalt mixtures during paving

For developing this model, five detection points were evenly distributed on the auger to avoid the uneven dispersion of the asphalt mixture on the screw distributor, as such uneven dispersion can affect the test results. A total of 15 samples were taken from each detection point, and the relationship between the gas emission concentration and paving width was as shown in Figure 4.

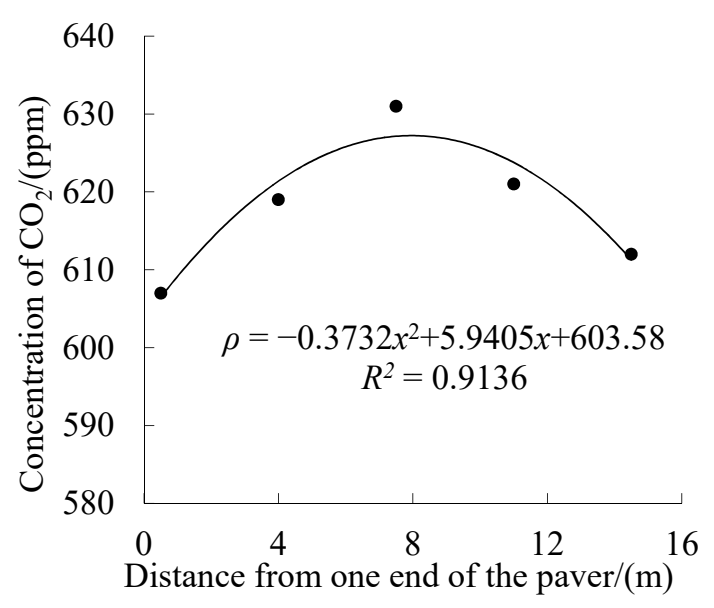

(a)

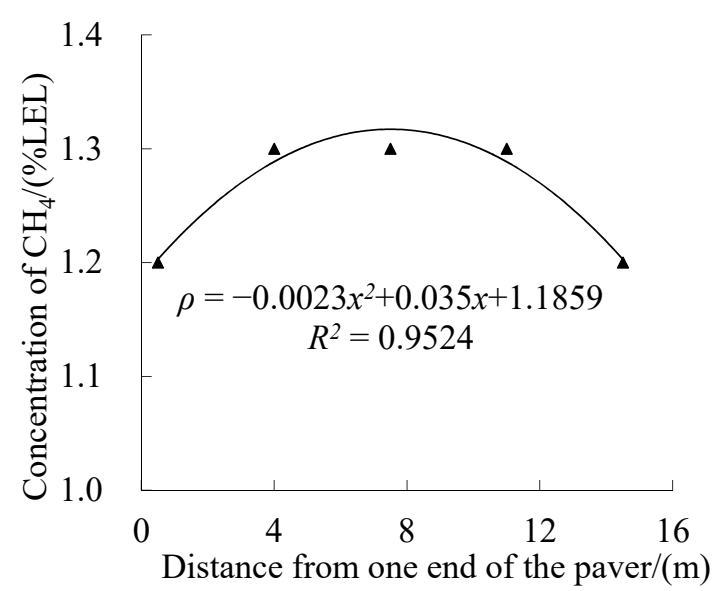

(b)

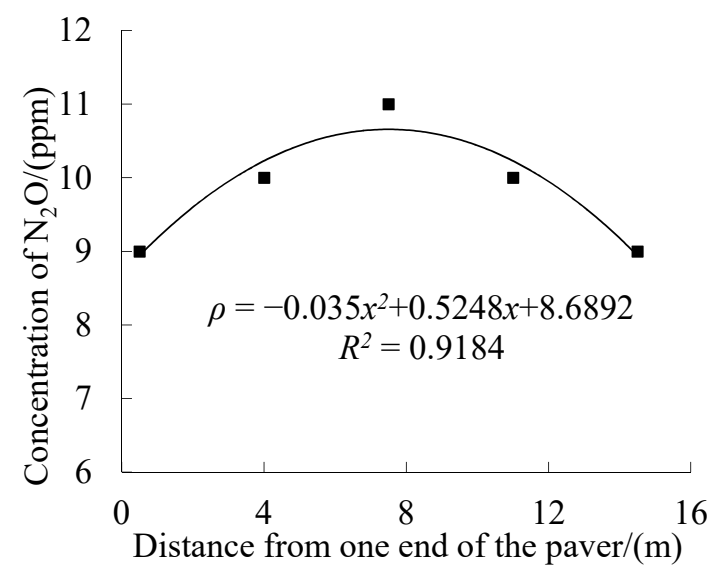

(c)

Figure 4. Relationship between gas emission concentration and paver detection points: (a) $\mathrm{CO}_{2}$;

(b) $\mathrm{CH}_{4}$; and (c) $\mathrm{N}_{2} \mathrm{O}$.

The volume and mass concentration of each point of the spiral distributor can be determined based on the relationship between the detection point and gas volume concentration, as shown in Figure 4. The gas diffusion rate $v_{3}$ of paving can be obtained based on the paving temperature and the relationship between the gas diffusion rate and the temperature (Figure 3). A ton of asphalt mixture is considered, and it discharges small amounts of greenhouse gases, resulting in large errors. Thus, the time required for paving $1 \mathrm{~m}$ is set as the calculation time. The calculated mass $G_{3}$ is determined in 
terms of density, pavement width, and pavement thickness. The calculation model of paving is finally obtained as shown in Equation (10):

$$
\left\{\begin{array}{l}
E_{c 7}=\frac{v_{3} \cdot t_{3} \cdot y_{1} \int_{0}^{x_{1}} \sum_{j=1}^{3} \rho_{7 j}(x) \cdot G W P_{j} d x}{10^{6} G_{3}} \\
G_{3}=\rho_{s} \cdot h \cdot x_{1} \cdot y_{1}
\end{array}\right.
$$

where $E_{c 7}$ is the carbon emission from the volatilization of the asphalt mixture during paving $(\mathrm{kg} / \mathrm{t}) ; v_{3}$ is the gas diffusion rate during paving $(\mathrm{m} / \mathrm{s}) ; t_{3}$ is the time required for paving $1 \mathrm{~m}(\mathrm{~s}) ; x_{1}$ is the paving width $(\mathrm{m}) ; y_{1}$ is the paving length $(\mathrm{m}) ; \rho_{7 j}$ is the mass concentration of gas $\left(\mathrm{mg} / \mathrm{m}^{3}\right) ; G_{3}$ is the mass of the asphalt mixture for paving $1 \mathrm{~m}(\mathrm{t}) ; \rho_{s}$ is the density of the mixture $\left(\mathrm{g} / \mathrm{cm}^{3}\right) ;$ and $h$ is the thickness of the surface layer $(\mathrm{m})$.

(4) Carbon emission calculation model of asphalt mixtures during rolling

During the rolling process, greenhouse gas detection takes place from the beginning of the initial compaction to the moment when the emission concentration is close to the atmospheric concentration. The relationship between the gas concentration and detection time of rolling is shown in Figure 5.

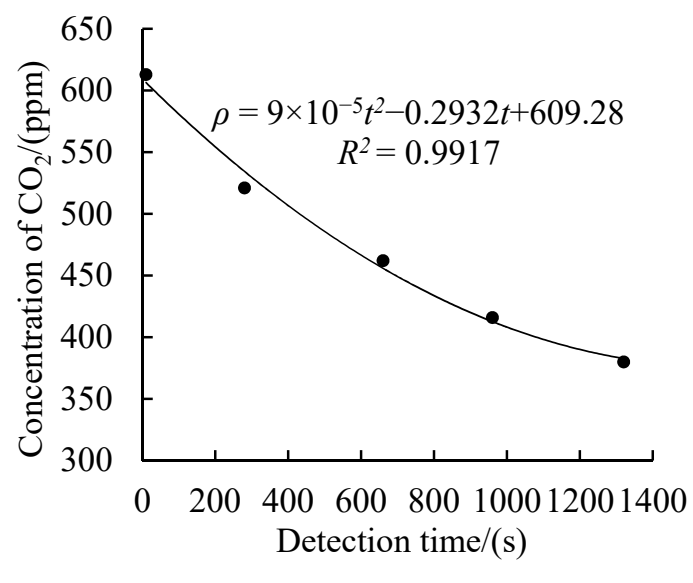

(a)

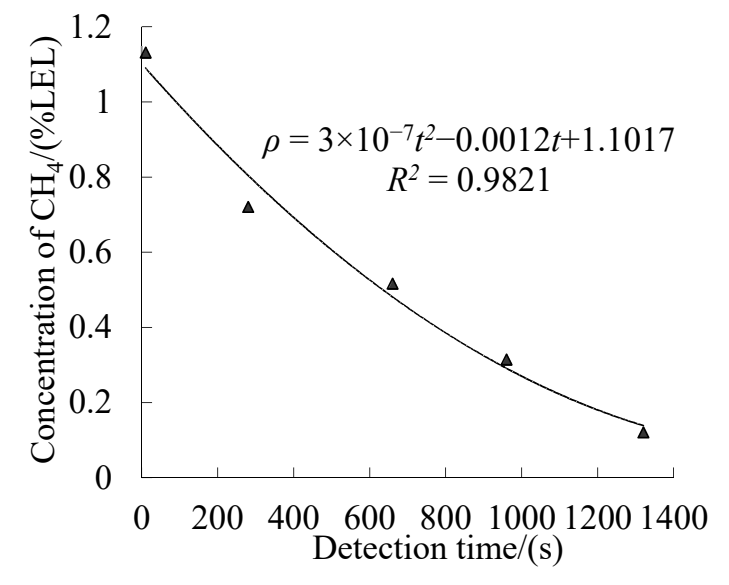

(b)

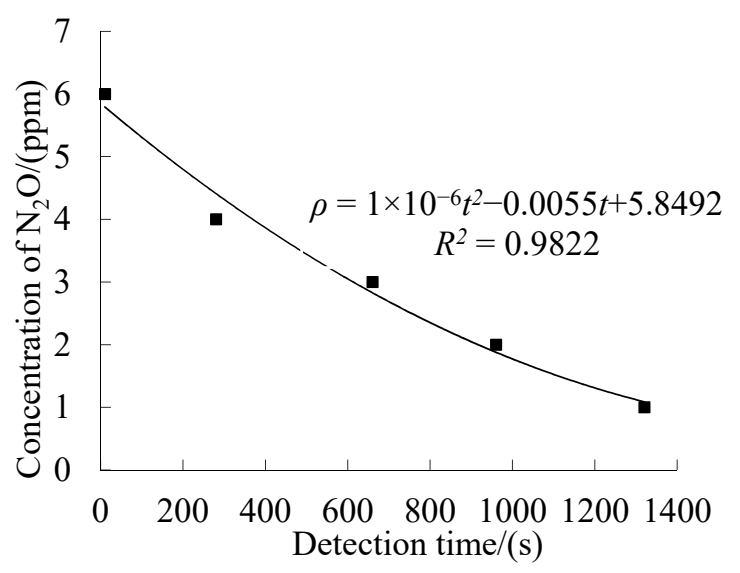

(c)

Figure 5. Relationship between greenhouse gas concentration and detection time: (a) $\mathrm{CO}_{2} ;(\mathbf{b}) \mathrm{CH}_{4}$; and (c) $\mathrm{N}_{2} \mathrm{O}$. 
According to Figure 3 , the gas diffusion rate of $v_{4}$ can be acquired; the greenhouse gas concentration of $\rho_{8 j}$ can be determined from Figure 5. The width and mileage parameters should be consistent during the paving process because paving and rolling are conducted on the same road section. Therefore, for paving, the rolling length of $1 \mathrm{~m}$ is set as the longitudinal parameter. The calculated quality is the same as that for paving. The calculation model for rolling is shown in Equation (11):

$$
\left\{\begin{array}{l}
E_{c 8}=\frac{v_{4} \cdot x_{1} \cdot y_{1} \int_{0}^{t_{4}} \sum_{j=1}^{3} \rho_{8 j}(t) \cdot G W P_{j} d t}{10^{6} G_{3}} \\
G_{3}=\rho_{s} \cdot x_{1} \cdot y_{1} \cdot h
\end{array}\right.
$$

where $E_{C 8}$ is the carbon emission from the volatilization of the asphalt mixture during rolling $(\mathrm{kg} / \mathrm{t})$; $v_{4}$ is the gas diffusion rate during rolling $(\mathrm{m} / \mathrm{s}) ; t_{4}$ is the time required for greenhouse gas emission concentration to approach the atmospheric concentration during rolling $(\mathrm{s})$; and $\rho_{8 j}$ is the gas mass concentration during rolling $\left(\mathrm{mg} / \mathrm{m}^{3}\right)$.

(5) Calculation model of total carbon emission from the volatilization of asphalt mixtures

The total calculation model is obtained based on the carbon emission calculation models of the asphalt mixture during mixing, transportation, paving, and rolling, as shown in Equation (12):

$$
E_{c}=\sum_{i=5}^{8} E_{c i}
$$

where $E_{c}$ is the total carbon emission from the volatilization of the asphalt mixture $(\mathrm{kg} / \mathrm{t})$ and $E_{c i}$ is the carbon emission from the volatilization of asphalt the mixture in $i$ process $(\mathrm{kg} / \mathrm{t})$.

\section{Low-Carbon Technology in the Construction of Asphalt Pavements}

Today, there is considerable focus on the concept of "environmental protection and energy conservation", and low-carbon technology for asphalt pavement construction is gaining attention [33-39]. Therefore, low-carbon technologies are proposed based on the two types of carbon emissions, and mainly involve carbon emission reduction in terms of energy consumption and asphalt mixtures. The study of carbon emission reduction considering energy consumption mainly focuses on natural gas. In this approach, the aim is to decrease carbon emission by reducing consumption and improving energy utilization. This study also proposes the use of low-carbon asphalt mixtures and the adoption of warm mixing technology to reduce the carbon emission from the volatilization of asphalt mixtures.

\subsection{Low-Carbon Asphalt Mixture}

An additional low-carbon agent in the mixing of asphalt or asphalt mixtures can be used to reduce the mixing temperature of the asphalt mixture (the mixing temperature of low-carbon asphalt mixtures is generally $110-140{ }^{\circ} \mathrm{C}$ ). The low-carbon agent is a substance capable of reducing the viscosity of the asphalt and aggregate. Therefore, a lubricating structure is formed, and the friction between the binder and aggregate of the asphalt mixture during mixing is reduced, thereby reducing the mixing temperature. This phenomenon reduces the carbon emission from the volatilization of asphalt mixtures itself.

\subsection{Warm Mixing Technology}

In warm mixing technology, a viscosity reducer is added to reduce the viscosity of asphalt mixtures at a low mixing temperature (the mixing temperature in the warm mixing technology is $130-150{ }^{\circ} \mathrm{C}$ ). Under the requirements of good construction and long-term road performance of asphalt pavements, the warm mixing technology reduces the overall temperature of the mixture, saving a large amount of the heating energy. This reduction minimizes harmful gas emissions and reduces energy consumption. 


\section{Case Studies with Results and Discussion}

\subsection{Case Study: Calculation of Carbon Emission}

For carbon emission from energy consumption, the details are as follows:

Huangyan Expressway was selected for a case study for quantitative calculation to verify the reliability and practicality of the carbon emission models of energy consumption. Results show that the oxidation rate and density of diesel are 0.98 and $0.835 \mathrm{~g} / \mathrm{cm}^{3}$, respectively, and the combustion rates of coal and heavy oil are 0.9 and 0.98 , respectively. The energy consumption and calculation parameters for Huangyan Expressway were used in Equations (2)-(4), and the carbon emissions from energy consumption were obtained. The results are listed in Table 4.

Table 4. Carbon emission in the energy consumption of Huangyan Expressway.

\begin{tabular}{ccccccccc}
\hline Process & $\begin{array}{c}\text { Yard } \\
\text { Stacking }\end{array}$ & $\begin{array}{c}\text { Aggregate } \\
\text { Feeding }\end{array}$ & $\begin{array}{c}\text { Aggregate } \\
\text { Heating }\end{array}$ & $\begin{array}{c}\text { Asphalt } \\
\text { Heating }\end{array}$ & Transportation & Paving & Rolling & Total \\
\hline$E_{e} /\left(\mathrm{kg} \cdot \mathrm{t}^{-1}\right)$ & 0.355 & 0.561 & 20.684 & 3.802 & 0.088 & 0.465 & 0.586 & 26.54 \\
\hline
\end{tabular}

Table 4 shows that the process with the highest carbon emission with regards to energy consumption is aggregate heating, followed by asphalt heating; the carbon emission of other processes is small. In all, calculations were performed for 12 expressways in different regions of China to eliminate the contingency of the data results of a single road segment. The carbon emissions from the energy consumption of 12 expressways were obtained, and the calculation method was the same as the example of the Huangyan expressway, the main difference being the energy consumption (see Table 2). These results are shown in Figure 6.

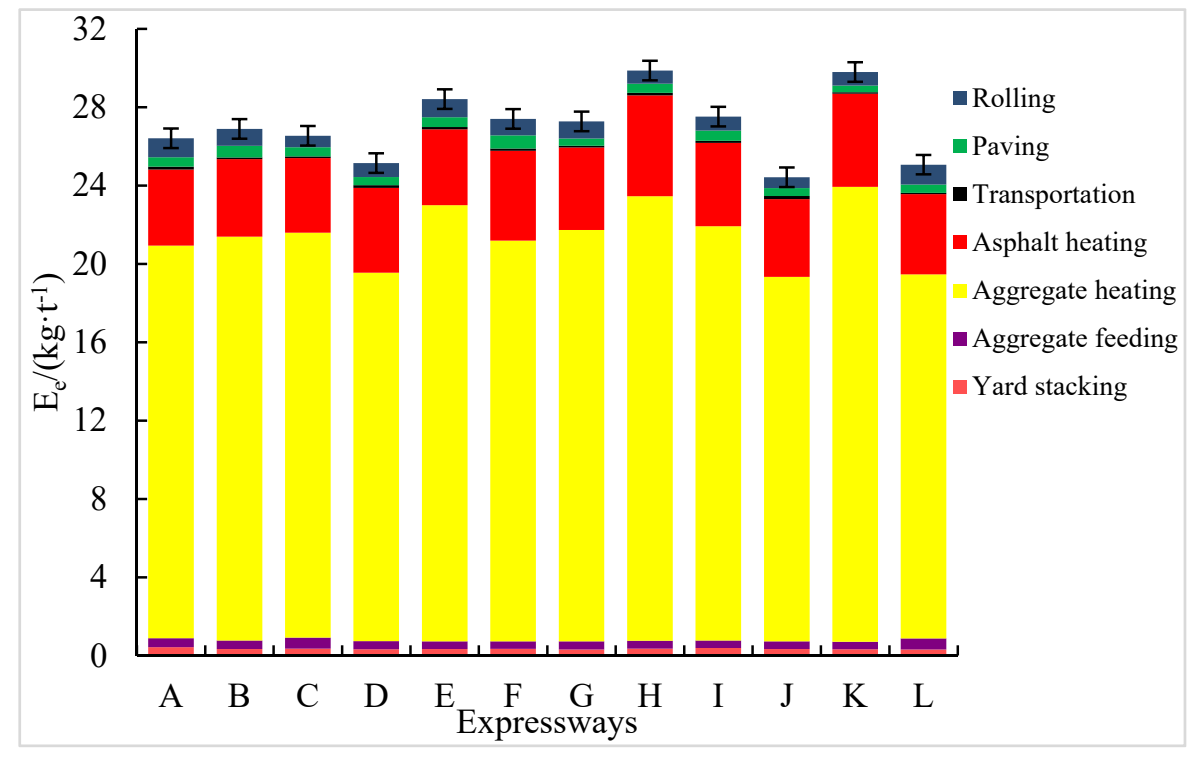

Figure 6. Carbon emissions in energy consumption of 12 expressways. Note: the carbon emission of energy consumption generated by transportation used 1 ton of asphalt mixture for $1 \mathrm{~km}$ as the quantitative calculation standard, and the remaining processes used 1 ton of the asphalt mixture as the calculation standard.

In Figure 6, the average carbon emission from energy consumption of 12 expressways is regarded as the representative value; the figure shows that carbon emission during aggregate heating is the highest, reaching $76.41 \%$ of the total carbon emission, followed by asphalt heating, which accounts for $15.67 \%$. Thus, aggregate heating and asphalt heating are the main sources that account for $92.08 \%$ of the 
total carbon emission from energy consumption because the fuel used is mainly heavy oil. Therefore, carbon emission can be reduced by changing the fuel type or promoting the use of clean energy.

For carbon emission from volatilization of asphalt mixture, the details are as follows:

Huangyan Expressway was also selected for quantitative calculations to verify the reliability and practicability of models for carbon emission from the volatilization of asphalt mixtures. The multigas detector used in gas detection had a cooling device that maintained its temperature close to the atmospheric temperature. Hence, the atmospheric temperature of $35^{\circ} \mathrm{C}$ on the day of project inspection was used as the temperature parameter. The instrument was also in contact with the atmosphere; therefore, the atmospheric pressure of 101,325 Pa was taken as the parameter. Field investigation results showed that the asphalt-aggregate ratio was $4.3 \%$; the volume of the asphalt storage tank was $5.6 \times 10^{-3} \mathrm{~m}^{3}$; and the mass of the asphalt sample was $1.1 \mathrm{~kg}$. The calculation parameters of mixing, transportation, paving, and rolling are listed in Tables 5 and 6 . The concentrations of greenhouse gases are listed in Table 7.

Table 5. Calculation parameters of mixing and transportation for the Huangyan Expressway.

\begin{tabular}{ccccccccc}
\hline Parameter & $v_{1} /\left(\mathbf{m} \cdot \mathbf{s}^{-1}\right)$ & $v_{2} /\left(\mathbf{m} \cdot \mathbf{s}^{-1}\right)$ & $t_{1} /(\mathbf{s})$ & $t_{2} /(\mathbf{s})$ & $S_{1} /\left(\mathbf{m}^{2}\right)$ & $S_{2} /\left(\mathbf{m}^{2}\right)$ & $G_{1} /(\mathbf{t})$ & $G_{2} /(\mathbf{t})$ \\
\hline Value & 0.32 & 0.31 & 12 & 144 & 1.44 & 14.35 & 4 & 45 \\
\hline
\end{tabular}

Table 6. Calculation parameters of paving and rolling for the Huangyan Expressway.

\begin{tabular}{ccccccccc}
\hline Parameter & $x_{1} /(\mathrm{m})$ & $y_{1} /(\mathrm{m})$ & $v_{3} /\left(\mathbf{m} \cdot \mathbf{s}^{-\mathbf{1}}\right)$ & $v_{4} /\left(\mathbf{m} \cdot \mathbf{s}^{-1}\right)$ & $t_{3} /(\mathrm{s})$ & $t_{4} /(\mathrm{s})$ & $h /(\mathrm{m})$ & $\rho_{s} /\left(\mathrm{g} \cdot \mathrm{cm}^{-3}\right)$ \\
\hline Value & 15.1 & 1 & 0.5 & 0.2 & 20 & 1320 & 0.06 & 2.46 \\
\hline
\end{tabular}

Table 7. Mean values of detection samples of the Huangyan Expressway.

\begin{tabular}{ccccc}
\hline Detection Samples & Mixing & Transportation & Paving & Rolling \\
\hline $\mathrm{CO}_{2} /(\mathrm{ppm})$ & 605 & 642.8 & 620 & 478.4 \\
$\mathrm{CH}_{4} /(\% \mathrm{LLL})$ & 1.2 & 1.3 & 1.28 & 0.56 \\
$\mathrm{~N}_{2} \mathrm{O} /(\mathrm{ppm})$ & 10.2 & 11.2 & 9.7 & 3.2 \\
\hline
\end{tabular}

The relative molecular mass of greenhouse gases, the temperature of $35{ }^{\circ} \mathrm{C}$, the pressure of $101,325 \mathrm{~Pa}$, and the calculation parameters in Tables 5-7 were substituted into Equations (5)-(12). The carbon emission of the asphalt mixture in Huangyan Expressway was then obtained; the results are presented in Table 8.

Table 8. Carbon emission from volatilization of the asphalt mixture in Huangyan Expressway.

\begin{tabular}{cccccc}
\hline Process & Mixing & Transportation & Paving & Rolling & Total \\
\hline $\mathrm{E}_{\mathrm{c}} /\left(\mathrm{kg} \cdot \mathrm{t}^{-1}\right)$ & 0.022 & 0.245 & 1.120 & 15.935 & 17.358 \\
\hline
\end{tabular}

The data in Table 8 show that the carbon emissions from the volatilization of the asphalt mixture in the various processes are different. Among the processes, rolling caused the highest emission, followed by paving, while the emissions of other processes were small (especially in mixing, less than $0.1 \mathrm{~kg} \cdot \mathrm{t}^{-1}$, so the $\mathrm{E}_{\mathrm{c}}$ of mixing can be neglected). The calculation method of carbon emission from the volatilization of 12 expressways is the same as the Huangyan expressway, and these carbon emissions were obtained by substituting the calculation parameters into the equations. The results are shown in Figure 7.

Figure 7 shows that the total carbon emission from the volatilization of the asphalt mixture of the 12 expressways, which is lower than the carbon emission arising from energy consumption of the same expressways. Among them, the carbon emissions of seven expressways are much higher, more than $16 \mathrm{~kg} \cdot \mathrm{t}^{-1}$; the expressways D, F, G, K, and L have lower emissions, but still more than $5 \mathrm{~kg} \cdot \mathrm{t}^{-1}$. 
The average carbon emission of each process was considered as the representative value; a comparison of these values showed that carbon emission during rolling was the highest, accounting for $91.50 \%$ of the total carbon emission of the asphalt mixture, followed by paving, which accounted for $7.03 \%$. These two processes together accounted for $98.53 \%$ of the emissions, and thus, they are the main sources in terms of carbon emission from the volatilization of asphalt mixtures. This finding is attributed to the characteristics of the paved asphalt mixture, which takes a long time to reduce greenhouse gas concentrations from a high value to the atmospheric concentration. Moreover, the emission time is generally 20-30 min, thereby causing high-carbon emission during paving and rolling processes.

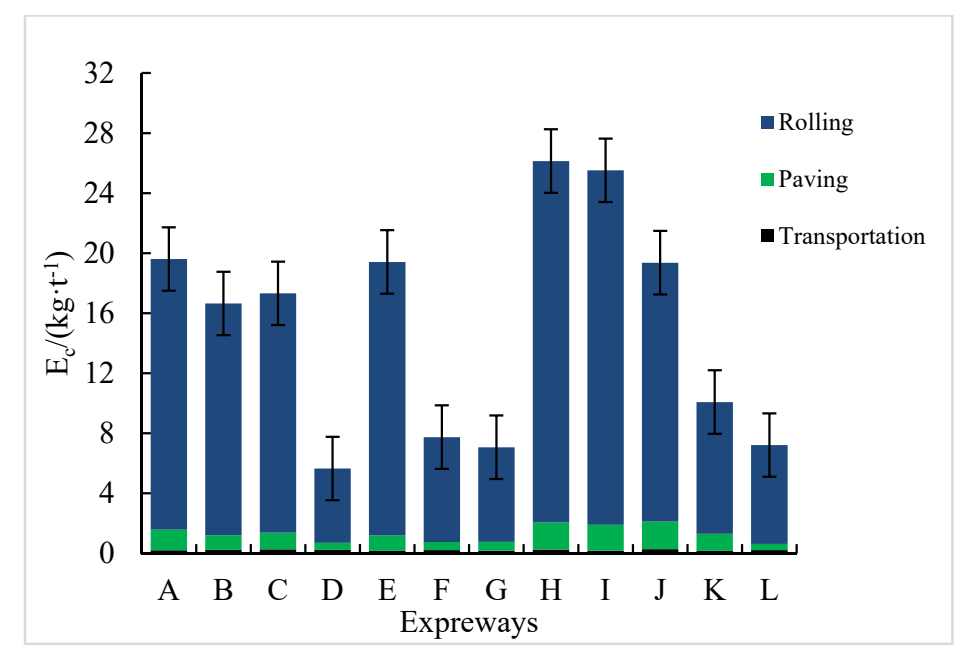

Figure 7. Carbon emissions of asphalt mixture in 12 expressways. Note: the carbon emission of the mixture generated by transportation used 1 ton of asphalt mixture for $1 \mathrm{~km}$ as the quantitative calculation standard, and other processes used 1 ton of the asphalt mixture as the calculation standard.

\subsection{Discussion of the Case Study: Calculation of Total Carbon Emission}

The total carbon emissions in the construction of the asphalt pavements of the 12 expressways were analyzed and discussed to evaluate and determine the overall carbon emission of asphalt pavements based on the two aforementioned case studies. The equation is shown in Equation (13).

$$
E=\sum_{i=1}^{8} E_{e i}(i \neq 5)+\sum_{i=5}^{8} E_{c i}
$$

According to Tables 1-3 and Equations (2)-(4), carbon emission from energy consumption $\left(E_{e}\right)$ of each expressway was obtained; According to Tables 5-8 and Equations (5)-(12), carbon emission from the volatilization of asphalt mixtures $\left(E_{c}\right)$ of each expressway was obtained. The calculation results show that $E_{e}$ is $342.42 \mathrm{~kg} \cdot \mathrm{t}^{-1}$; the total carbon emission from the volatilization of asphalt mixtures $E_{c}$ is $182 \mathrm{~kg} \cdot \mathrm{t}^{-1}$; and the total carbon emission $E$ is $506.52 \mathrm{~kg} \cdot \mathrm{t}^{-1}$. Therefore, the carbon emission ratio of energy consumption and asphalt mixture is $3: 2$, and the proportion of carbon emission generated by the asphalt mixture itself is high. This observation should be considered in the construction of asphalt pavements.

To summarize, although the total carbon emissions of different projects vary, the overall trend is consistent. Processes causing carbon emissions, in decreasing order, are aggregate heating, rolling, asphalt heating, mixing, and paving; the contributions of yard stacking, aggregate feeding, and transportation processes are relatively small. Among the four high emission processes, aggregate heating, asphalt heating, and mixing mainly generated emissions via energy consumption; rolling mainly generated emissions from the asphalt mixture itself. 


\subsection{Case Study: Calculation of Carbon Emission Reduction}

For the reduction of carbon emission from energy consumption, the details are as follows:

Natural gas was considered to conduct carbon emission reduction research for two high-carbon emission processes (aggregate and asphalt heating), calculated considering carbon emission from energy consumption. Taking Huangyan Expressway as the case study and using the data in Table 2 and Equations (2)-(4), the carbon emission reduction effects on using natural gas were obtained. The results are shown in Table 9.

Table 9. Carbon emission reduction regarding energy consumption.

\begin{tabular}{cccc}
\hline Construction Process & Energy Type & $E_{e} /\left(\mathbf{k g} \cdot \mathbf{t}^{-\mathbf{1}}\right)$ & Reduction Rate (\%) \\
\hline \multirow{2}{*}{ Aggregate heating } & Heavy oil (before) & 6.524 & $/$ \\
& Natural gas (after) & 4.718 & 27.68 \\
\multirow{2}{*}{ Asphalt heating } & Coal (before) & 1.823 & $/$ \\
& Natural gas (after) & 1.077 & 40.92 \\
\hline
\end{tabular}

Note: reduction rate (aggregate heating) $=\mid E_{e}$ (heavy oil) $-E_{e}$ (natural gas) $\mid / E_{e}$ (heavy oil) $\times 100 \%$; reduction rate (asphalt heating) $=\mid E_{e}(\mathrm{coal})-E_{e}($ natural gas $) \mid / E_{e}($ coal $) \times 100 \%$.

A comparative analysis of the carbon emission reduction effects of energy showed that natural gas can effectively reduce carbon emission by $27.68 \%$ compared with heavy oil during aggregate heating. In asphalt heating, natural gas can reduce carbon emission by $40.92 \%$ compared with coal. Thus, changing the fuel type can clearly help reduce carbon emissions attributed to energy consumption and reduction rate.

For the reduction of carbon emission from the volatilization of asphalt mixtures, the details are as follows:

Low-carbon asphalt mixtures and warm mixing technology are compared in terms of carbon emission reduction. Taking Huangyan Expressway as the case study and based on an indoor simulation test, styrene-butadiene-styrene block copolymer (SBS) was added to modify asphalt (grade I-D); the asphalt concrete was medium grained (AC-16); it was used for the middle surface layer; and the thickness was $6 \mathrm{~cm}$; the asphalt used corresponded to Huangyan Expressway; a 3\% sasobit warm mixing agent was used as the optimum mix amount, and a 3\% low carbon agent was selected as the comparative study. The carbon emission reduction results are presented in Table 10.

Table 10. Carbon emission reduction regarding carbon emission from the volatilization of asphalt mixtures.

\begin{tabular}{|c|c|c|c|c|}
\hline Mix & Type & Mixing Temperature $\left({ }^{\circ} \mathrm{C}\right)$ & $E_{c} /\left(\mathbf{k g} \cdot \mathbf{t}^{-1}\right)$ & Reduction Rate (\%) \\
\hline \multicolumn{2}{|c|}{ Hot mix asphalt mixture } & $150-180^{\circ} \mathrm{C}$ & 0.022 & / \\
\hline Warm asphalt & Sasobit & $130-150{ }^{\circ} \mathrm{C}$ & 0.016 & 27.3 \\
\hline mixture & Low-carbon agent & $110-140{ }^{\circ} \mathrm{C}$ & 0.0107 & 48.6 \\
\hline
\end{tabular}

The data in Table 10 show that carbon emission during mixing reduced by $27.3 \%$ when warm mixing technology was used. The application of low-carbon asphalt mixture technology reduced carbon emission by $48.6 \%$. Therefore, warm mixing and low-carbon asphalt mixture technologies have evident emission reduction effects and can be applied for asphalt mixtures.

\subsection{Discussion of Case Studies: Comparison of Carbon Emission Reduction}

The data listed in Table 9 show that among the three heating energy sources, natural gas has more significant emission reduction effect. Therefore, the use of natural gas instead of heavy oil or coal can be considered as one of the low-carbon emission reduction technologies in construction, which should be preferred when economic. 
The data shown in Table 10 indicate that the low-carbon asphalt mixture has an evident emission reduction effect, reducing the carbon emission from the volatilization of the asphalt mixture by approximately $50 \%$; the low-carbon asphalt mixture is followed by warm mixing technology in terms of the effectiveness. In addition, compared with the hot mix asphalt mixture, the temperature of using the warm asphalt mixture decreased by about $20-30{ }^{\circ} \mathrm{C}$, and the temperature of using the low-carbon asphalt mixture decreased by $40{ }^{\circ} \mathrm{C}$. Thus, the heating temperature of aggregate and asphalt can be greatly controlled, thereby reducing the energy consumption.

The carbon emission calculation models for asphalt pavement construction presented in this paper not only define the type of carbon emission and accurately describe the emission of pollutants, but also provide reference values for the calculation of the emission reduction effect of low-carbon technologies such as natural gas, warm mixing technology, and low-carbon asphalt mixtures.

\section{Conclusions}

The proposed models provide effective calculations of the carbon emissions arising during the construction of expressways. Furthermore, the calculation models were demonstrated by comparing the carbon emission reduction of different low-carbon technologies. Some conclusions are as follows:

(1) For the calculation of carbon emission from energy consumption, the results showed that the carbon emission of aggregate heating is the highest, $76.41 \%$ of the total carbon emission, followed by asphalt heating, accounting for $15.67 \%$. Therefore, aggregate heating and asphalt heating are the main carbon emission sources of energy consumption, accounting for $92.08 \%$ of the total carbon emission of energy consumption.

(2) For the calculation of carbon emission from the volatilization of the asphalt mixture, the results showed that carbon emission during rolling was the highest, accounting for $91.50 \%$ of the total carbon emission of the asphalt mixture, followed by paving, which accounted for $7.03 \%$. These two processes together accounted for $98.53 \%$ of the emissions, and thus, they are the main carbon emission sources from the volatilization of the asphalt mixture.

(3) The results show that the carbon emission ratio between the carbon emissions from energy consumption and asphalt mixtures is close to 3:2. The energy consumption processes with high-carbon emission are aggregate heating and asphalt heating, which are attributed to the asphalt mixture in the rolling and paving of asphalt mixture.

(4) Carbon emissions in energy consumption in aggregate and asphalt heating were reduced by $27.68 \%$ and $40.92 \%$, respectively, by using natural gas. Using warm mixing and low-carbon asphalt mixture technology can reduce carbon emissions of the asphalt mixture by $27.3 \%$ and $48.6 \%$, respectively, and the effect on emission reduction is remarkable.

The proposed carbon emission calculation methods provide theoretical bases for sustainable expressway construction. However, there are still some limitations. First, owing to the limited time, there is a lack of consideration of carbon emissions during raw material production, road operation, maintenance, and demolition. Future studies will need to cover the entire life cycle. Second, the results of the empirical analysis depend on data sources in China. Determining whether these results are applicable to other countries requires further testing.

Author Contributions: Conceptualization, B.P., X.T., and S.C.; data curation, X.T.; formal analysis, B.P., X.T., and S.C.; funding acquisition, W.L.; investigation, S.C.; methodology, B.P. and X.T.; validation, B.P., X.T., W.L., and G.X.; writing—original draft, X.T.; writing-review and editing, B.P., S.C., W.L., and G.X. All authors have read and agreed to the published version of the manuscript.

Funding: This research is supported by the scientific project from the Natural Science Foundation of Shaanxi Province under project (No. 2011JM7001), the Shaanxi Provincial Science and Technology Department Project (No. 15-08K), and the Gansu Provincial Department of Transportation Research Project (No. 201227). The authors gratefully acknowledge their financial support.

Conflicts of Interest: The authors declare that they have no conflict of interest. 


\section{References}

1. Erickson, L.E. Reducing greenhouse gas emissions and improving air quality: Two global challenges. Environ. Prog. Sustain. Energy 2017, 36, 982-988. [CrossRef] [PubMed]

2. Schaltegger, S.; Martinov-Bennie, N. Greenhouse gas emissions reporting and assurance: Reflections on the current state. Sustain. Account. Manag. Policy J. 2012, 3, 244-251.

3. Quiros, D.C.; Smith, J.; Thiruvengadam, A.; Huai, T.; Hu, S. Greenhouse gas emissions from heavy-duty natural gas, hybrid, and conventional diesel on-road trucks during freight transport. Atmos. Environ. 2017, 168, 36-45. [CrossRef]

4. Radić, V.; Bliss, A.; Beedlow, A.C. Regional and global projections of twenty-first century glacier mass changes in response to climate scenarios from global climate models. J. Clim. Dyn. 2014, 42,37-58. [CrossRef]

5. Ouyang, B.; Zhang, Y.; Li, Z.; Guo, J. Methodology of Urban Transport Carbon Emission Calculation Applicable for China: Guangzhou as a Case Study; Springer: Berlin/Heidelberg, Germany, 2015. [CrossRef]

6. Pérez-Bernabeu, E.; Juan, A.A.; Faulin, J.; Barrios, B.B. Horizontal cooperation in road transportation: A case illustrating savings in distances and greenhouse gas emissions. Int. Trans. Oper. Res. 2015, 22, 585-606. [CrossRef]

7. Qiao, Y.; Dawson, A.; Parry, T.; Flintsch, G. Life cycle cost of flexible pavements and climate variability: Case studies from Virginia. Struct. Infrastruct. Eng. 2019, 15, 1665-1679. [CrossRef]

8. Kim, S. Decomposition Analysis of Greenhouse Gas Emissions in Korea's Transportation Sector. Sustainability 2019, 11, 1986. [CrossRef]

9. Jonas, M.; Bun, R.; Nahorski, Z.; Marland, G.; Gusti, M.; Danylo, O. Quantifying greenhouse gas emissions. Mitig. Adapt. Strateg. Glob. Chang. 2019, 24, 839-852. [CrossRef]

10. Hatmoko, J.U.D.; Hidayat, A.; Setiawati, A.; Prasetyo, S.C.A. Measuring Carbon Footprint of Flexible Pavement Construction Project in Indonesia. E3s Web Conf. 2018, 31, 07001. [CrossRef]

11. Cass, D.; Mukherjee, A. Calculation of greenhouse gas emissions for highway construction operations by using a hybrid life-cycle assessment approach: Case study for pavement operations. J. Constr. Eng. Manag. 2011, 137, 1015-1025. [CrossRef]

12. Wang, T.; Lee, I.S.; Kendall, A.; Harvey, J.; Lee, E.-B.; Kim, C. Life cycle energy consumption and GHG emission from pavement rehabilitation with different rolling resistance. J. Clean. Prod. 2012, 33, 86-96. [CrossRef]

13. Wang, H.; Al-Saadi, I.; Lu, P.; Jasim, A. Quantifying greenhouse gas emission of asphalt pavement preservation at construction and use stages using life-cycle assessment. Int. J. Sustain. Transp. 2019, 14, 25-34. [CrossRef]

14. White, P.; Golden, J.S.; Biligiri, K.P.; Kaloush, K. Modeling climate change impacts of pavement production and construction. Resour. Conserv. Recycl. 2010, 54, 776-782. [CrossRef]

15. Kleine, R.D.D.; Keoleian, G.A.; Miller, S.A.; Burnham, A.; Sullivan, J.L. Impact of Updated Material Production Data in the GREET Life Cycle Model. J. Ind. Ecol. 2014, 18, 356-365. [CrossRef]

16. Aurangzeb, Q.; Al-Qadi, I.L.; Ozer, H.; Yang, R. Hybrid life cycle assessment for asphalt mixtures with high RAP content. Resour. Conserv. Recycl. 2014, 83, 77-86. [CrossRef]

17. Giunta, M.; Mistretta, M.; Praticò, F.G.; Gulotta, M.T. Environmental Sustainability and Energy Assessment of Bituminous Pavements Made with Unconventional Materials. In Proceedings of the 5th International Symposium on Asphalt Pavements E Environment (APE); Pasetto, M., Partl, M., Tebaldi, G., Eds.; Lecture Notes in Civil Engineering; ISAP APE 2019; Springer: Padova, Italy, 2020; p. 48. [CrossRef]

18. Bressi, S.; Santos, J.; Giunta, M.; Pistonesi, L.; Presti, D.L. A comparative life-cycle assessment of asphalt mixtures for railway sub-ballast containing alternative materials. Resour. Conserv. Recycl. 2018, 137, 76-88. [CrossRef]

19. Praticò, F.G.; Giunta, M.; Mistretta, M.; Gulotta, T.M. Energy and Environmental Life Cycle Assessment of Sustainable Pavement Materials and Technologies for Urban Roads. Sustainability 2020, 12, 704. [CrossRef]

20. Feng, M.; Aimin, S.; Ruiyu, L.; Huang, Y.; Wang, C. Greenhouse Gas Emissions from Asphalt Pavement Construction: A Case Study in China. Int. J. Environ. Res. Public Health 2016, 13, 351. [CrossRef]

21. Ma, F.; Sha, A.; Yang, P.; Huang, Y. The Greenhouse Gas Emission from Portland Cement Concrete Pavement Construction in China. Int. J. Environ. Res. Public Health 2016, 13, 632. [CrossRef]

22. Lai, T.M.; To, W.M.; Lam, K.H.; Lo, W.C.; Chung, W.L. Electricity consumption in Hong Kong: Trend analysis and greenhouse gases emission. Hkie Trans. 2014, 21, 81-88. [CrossRef] 
23. Jacobs, J.M.; Meagher, W.; Daniel, J.; Linder, E. Feedbacks from Green House Gas Emissions on Roads: A General Methodology for Analyzing Global Warming on Linear Infrastructure with a Case Study in the Northeastern U.S. Presented at American Geophysical Union Fall Meeting 2011, San Francisco, CA, USA, 5-9 December 2011.

24. Thives, L.P.; Ghisi, E. Asphalt mixtures emission and energy consumption: A review. Renew. Sustain. Energy Rev. 2017, 72, 473-484. [CrossRef]

25. Fernando, Y.; Hor, W.L. Impacts of Energy Management Practices on Energy Efficiency and Carbon Emissions Reduction: A Survey of Malaysian Manufacturing Firms. Resour. Conserv. Recycl. 2017, 126, 62-73. [CrossRef]

26. Christoph, W.; Simon, F.G. The Reduction of Greenhouse Gas Emissions through the Source-Separated Collection of Household Waste in Germany. In The Handbook of Environmental Chemistry; Springer: Cham, Switzerland, 2017. [CrossRef]

27. Wen, H.; Lu, J.; Vanreken, T.M. Modeling the Effects on Energy and Carbon Dioxide from the Use of Recycled Asphalt Pavement in Hot Mix Asphalt. Int. J. Sustain. Transp. 2014, 8, 249-261. [CrossRef]

28. Hamdi; Hadiwardoyo, S.P.; Correia, A.G.; Pereira, P. New optimization strategies of pavement maintenance: A case study for national road network in Indonesia using integrated road management system. In Green Process, Material, and Energy: A Sustainable Solution for Climate Change, Proceedings of the 3rd International Conference on Engineering, Technology, and Industrial Application (ICETIA 2016), Surakarta, Indonesia, 7-8 December 2016; AIP Publishing LLC: Melville, NY, USA, 2017. [CrossRef]

29. National Bureau of Statistics Energy Division. China Energy Statistical Yearbook; Beijing China Statistics Press: Beijing, China, 2014.

30. Eduardo, C.B.; Sabin, G.; Bundit, L.; Bundit, L.; Riitta, P.; Yasna, R.; Rob, S.; Kiyoto, T.; Tom, W.; Daniela, R.; et al. Refinement to the 2006 IPCC Guidelines for National Greenhouse Gas Inventories. The Intergovernmental Panel on Climate Change. 2019. Available online: https://www.ipcc.ch/report/2019-refinement-to-the-2006ipcc-guidelines-for-national-greenhouse-gas-inventories/ (accessed on 12 May 2019).

31. Bofeng, C.; Songli, Z.; Shengmin, Y. The Interpretation of 2019 refinement to the 2006 IPCC guidelines for national greenhouse gas inventory. Environ. Eng. 2019, 37, 1-11. [CrossRef]

32. Pachauri, R.; Reisinger, A. Climate change 2014: Synthesis report. Contribution of working groups i, ii and iii to the fifth assessment report of the intergovernmental panel on climate change. J. Roman. Stud. 2014, 4, 85-88. [CrossRef]

33. Sim, J.; Sim, J. The effect of new carbon emission reduction targets on an apartment building in South Korea. Energy Build. 2016, 127, 637-647. [CrossRef]

34. Fen, Y.; Jizhao, Z.; Jinting, W.; Kong, Z. Preparation Method of Low Carbon Asphalt Mixture. China Patent CN101837603A, 22 September 2010. (In Chinese).

35. Yongjoo, K.; Jaejun, L.; Cheolmin, B.; Sooahn, K.; Youngchan, S.; Jongcheol, S. Evaluation of warm-max asphalt mixtures using ledcap additive. Int. J. Pavement Eng. Asph. Technol. 2013, 14, 67-74. [CrossRef]

36. Biro, S.; Gandhi, T.; Amirkhanian, S. Midrange temperature rheological properties of warm asphalt binders. J. Mater. Civ. Eng. 2009, 21, 316-323. [CrossRef]

37. Salas, M.A.; Pérez-Acebo, H.; Calderón, V.; Gonzalo-Orden, H. Bitumen modified with recycled polyurethane foam for employment in hot mix asphalt. Ing. Investig. 2018, 38, 60-66. [CrossRef]

38. Barisa, A.; Rosa, M.; Laicane, I.; Sarmins, R. Application of Low-Carbon Technologies for Cutting Household GHG Emissions. Energy Procedia 2015, 72, 230-237. [CrossRef]

39. Perez-Martinez, M.; Marsac, P.; Gabet, T.; Hammoum, F.; Pouget, S. Effects of Ageing on Warm Mix Asphalts with High Rates of Reclaimed Asphalt Pavement. In Rilem International Conference on Mechanisms of Cracking $\mathcal{E}$ Debonding in Pavements; Springer: Dordrecht, The Netherlands, 2016. [CrossRef]

(C) 2020 by the authors. Licensee MDPI, Basel, Switzerland. This article is an open access article distributed under the terms and conditions of the Creative Commons Attribution (CC BY) license (http://creativecommons.org/licenses/by/4.0/). 